\title{
Preoperative diastolic function predicts the onset of left ventricular dysfunction following aortic valve replacement in high-risk patients with aortic stenosis
}

\author{
Marc Licker*1, Mustafa Cikirikcioglu², Cidgem Inan¹, Vanessa Cartier', Afksendyios Kalangos², Thomas Theologou², \\ Tiziano Cassina ${ }^{3}$ and John Diaper ${ }^{1}$
}

\begin{abstract}
Introduction: Left ventricular (LV) dysfunction frequently occurs after cardiac surgery, requiring inotropic treatment and/or mechanical circulatory support. In this study, we aimed to identify clinical, surgical and echocardiographic factors that are associated with LV dysfunction during weaning from cardiopulmonary bypass (CPB) in high-risk patients undergoing valve replacement for aortic stenosis.

Methods: Perioperative data were prospectively collected in 108 surgical candidates with an expected operative mortality $\geq 9 \%$. All anesthetic and surgical techniques were standardized. Reduced LV systolic function was defined by an ejection fraction $<40 \%$. Diastolic function of the LV was assessed using standard Doppler-derived parameters, tissue Doppler Imaging (TDI) and transmitral flow propagation velocity (Vp).

Results: Doppler-derived pulmonary flow indices and TDI could not be obtained in 14 patients. In the remaining 94 patients, poor systolic LV was documented in $14 \%(n=12)$ and diastolic dysfunction in $84 \%$ of patients $(n=89)$, all of whom had $V p<50 \mathrm{~cm} / \mathrm{s}$. During weaning from CPB, 38 patients (40\%) required inotropic and/or mechanical circulatory support. By multivariate regression analysis, we identified three independent predictors of LV systolic dysfunction: age (Odds ratio $[O R]=1.11 ; 95 \%$ confidence interval $(\mathrm{Cl}), 1.01$ to 1.22$)$, aortic clamping time $(\mathrm{OR}=1.04 ; 95 \% \mathrm{Cl}, 1.00$ to 1.08$)$ and $\mathrm{Vp}(\mathrm{OR}=0.65 ; 95 \% \mathrm{Cl}, 0.52$ to 0.81$)$. Among echocardiographic measurements, $\mathrm{Vp}$ was found to be superior in terms of prognostic value and reliability. The best cut-off value for Vp to predict LV dysfunction was $40 \mathrm{~cm} / \mathrm{s}$ (sensitivity of $72 \%$ and specificity $94 \%$ ). Patients who experienced LV dysfunction presented higher in-hospital mortality (18.4\% vs. $3.6 \%$ in patients without LV dysfunction, $P=0.044)$ and an increased incidence of serious cardiac events (81.6 vs. $28.6 \%$, $P<0.001)$.
\end{abstract}

Conclusions: This study provides the first evidence that, besides advanced age and prolonged myocardial ischemic time, LV diastolic dysfunction characterized by $V p \leq 40 \mathrm{~cm} / \mathrm{sec}$ identifies patients who will require cardiovascular support following valve replacement for aortic stenosis.

\section{Introduction}

More than 200,000 aortic valve replacements are performed annually worldwide and this number will continue to increase with the aging population. Over the last two decades, the operative mortality rate has steadily

* Correspondence: Marc-Joseph.Licker@hcuge.ch

1 Faculty of Medicine (University of Geneva) and Department of

Anaesthesiology, Pharmacology and Intensive Care, University Hospital, rue Gabrielle-Perret-Gentil, CH-1211 Geneva 14, Switzerland

Full list of author information is available at the end of the article declined from $10 \%$ to $4 \%$ along with improvements in surgical and anesthetic techniques [1-3]. However, left ventricular (LV) dysfunction requiring the administration of inotropic drugs often occurs after separation from cardiopulmonary bypass $(\mathrm{CPB})$ and has been associated with prolonged ICU and hospital stay [3,4]. Although this myocardial stunning usually resolves within 48 hours, it may lead to low cardiac output syndrome that has become the leading cause of postoperative death $[5,6]$. 
In large cohorts of patients undergoing cardiac surgery, post-CPB LV dysfunction has been linked to age, female gender, history of heart failure, recent myocardial infarct, low LV ejection fraction, prolonged aortic cross-clamping and complexity of surgery [7-11]. More recently, echocardiographic markers of preoperative LV diastolic dysfunction have been associated with difficulties in weaning patients from CPB $[12,13]$.

Although clinical signs (for example, pulmonary congestion, New York Heart Association [NYHA] classes) and markers of systolic LV function (for example, LV ejection fraction) have been studied extensively and incorporated in scoring algorithms for predicting perioperative risk, the prognostic value of diastolic dysfunction assessed by transoesophageal echocardiography (TEE) has not been examined in patients undergoing aortic valve replacement $[1,2,5,14,15]$. Besides pulsed-wave Doppler measurements of mitral inflow and pulmonary venous flow, evaluation of diastolic function has recently been improved with color M-mode transmitral flow propagation velocity $(\mathrm{Vp})$ and mitral valve annular velocities recorded by tissue Doppler imaging (TDI) $[16,17]$.

The main purpose of this study was to identify predictors of LV dysfunction in high-risk patients with aortic stenosis undergoing valvular replacement. Secondarily, we analyzed different Doppler parameters of diastolic function regarding their ability to predict post-CPB LV dysfunction.

\section{Materials and methods Study design and settings}

This prospective cohort study was conducted in a tertiary reference center, from January 2006 to December 2008. The study was approved by the Institutional Research Board of the University Hospital of Geneva and informed consent was obtained from each patient with severe aortic valvular stenosis who met the eligibility criteria. The Bernstein-Parsonnet algorithm was used to assess the operative risk of mortality [18]. During the study period, 108 patients were selected among a cohort of 145 surgical candidates undergoing elective aortic valve replacement, either isolated or combined with coronary artery bypass grafting or aortic root replacement. A predicted risk of mortality exceeding $9 \%$ was considered as an entry criteria. Exclusion criteria consisted of atrial fibrillation or flutter, implanted pacemaker, severe mitral stenosis or regurgitation, severe pulmonary hypertension (mean pulmonary artery pressure $\geq 45 \mathrm{mmHg}$ ), moderate-to-severe valvular aortic insufficiency and preoperative inotropic or ventilatory support. Patients were secondarily excluded if poor image quality precluded echocardiographic measurements. All patients were operated on by one of three board certified cardiac surgeons and were managed by the same team of cardiothoracic anesthesiologists.

\section{Perioperative patient management}

The usual medications were continued on the morning of the procedure, except diuretics and angiotensin-converting enzyme inhibitors or angiotensin II antagonists that were interrupted one day before. In the operating theatre, all patients were equipped with a noninvasive oscillometric monitor (brachial artery pressure), a radial arterial catheter, a central venous line and a bispectral monitor of the electroencephalogram (BIS Aspect Medical Systems A-2000 XP, Newton, Maryland, USA). Anesthesia management consisted of intra-thecal morphine, low doses of intravenous sufentanyl and an infusion of propofol to target BIS values between 40 and 60 . Cardiac preconditioning was also provided with inhaled isoflurane ( $1 \%$ to $1.5 \%$ ) before $\mathrm{CPB}$

A TEE probe (T6210 Omniplane II Philips Medical System, Andover, MA, USA) was introduced after anesthesia induction and images were digitally acquired before $\mathrm{CPB}$ and stored on a Philips Sonos 5500 Ultrasound Imaging system (Philips Medical Systems).

After full heparinization, normothermic CPB was instituted with a nonpulsatile flow $\left(2.2\right.$ to $2.5 \mathrm{~L} /$ minute $/ \mathrm{m}^{2}$ ) and alpha-stat control for acid-base management. The circuit and the membrane oxygenator were primed with 2 $\mathrm{L}$ of normal saline solution and mean arterial pressure (MAP) was maintained between 50 and $70 \mathrm{mmHg}$ with vasoactive medications as necessary. During aortic crossclamping, myocardial protection was achieved by intermittent antegrade infusion of cold blood. The aortic valve prosthesis (Carpentier-Edwards Perimount; Jt. Jude Medical Inc. Minneapolis, Minnesota, USA) was implanted in the supra-annular position with interrupted mattress sutures. All patients received tranexamic acid $(20 \mathrm{mg} / \mathrm{kg})$ and the transfusion threshold was a hematocrit less than 18 to $20 \%$ during CPB and less than $25 \%$ before/after $\mathrm{CPB}$.

At the end of the procedure, weaning from $\mathrm{CPB}$ was guided by TEE assessment and hemodynamic measurements. After de-airing the cardiac cavities and resumption of mechanical ventilation, the pump flow was gradually reduced allowing filling of the cardiac chambers. In addition to fluid loading, electrical atrio-ventricular pacing, vasopressors and inotropes drugs as well as intra-aortic balloon pump (IABP) were eventually introduced to target the specific hemodynamic endoints: LV end-diastolic diameter (up to preoperative values or 2.2 and $2.8 \mathrm{~cm} / \mathrm{m}^{2}$ ), MAP between 65 and $100 \mathrm{mmHg}$ and heart rate between 70 and 100 beats/minute (see Figure 1).

The investigators performing the TEE were not involved in any therapeutic decision during the weaning 


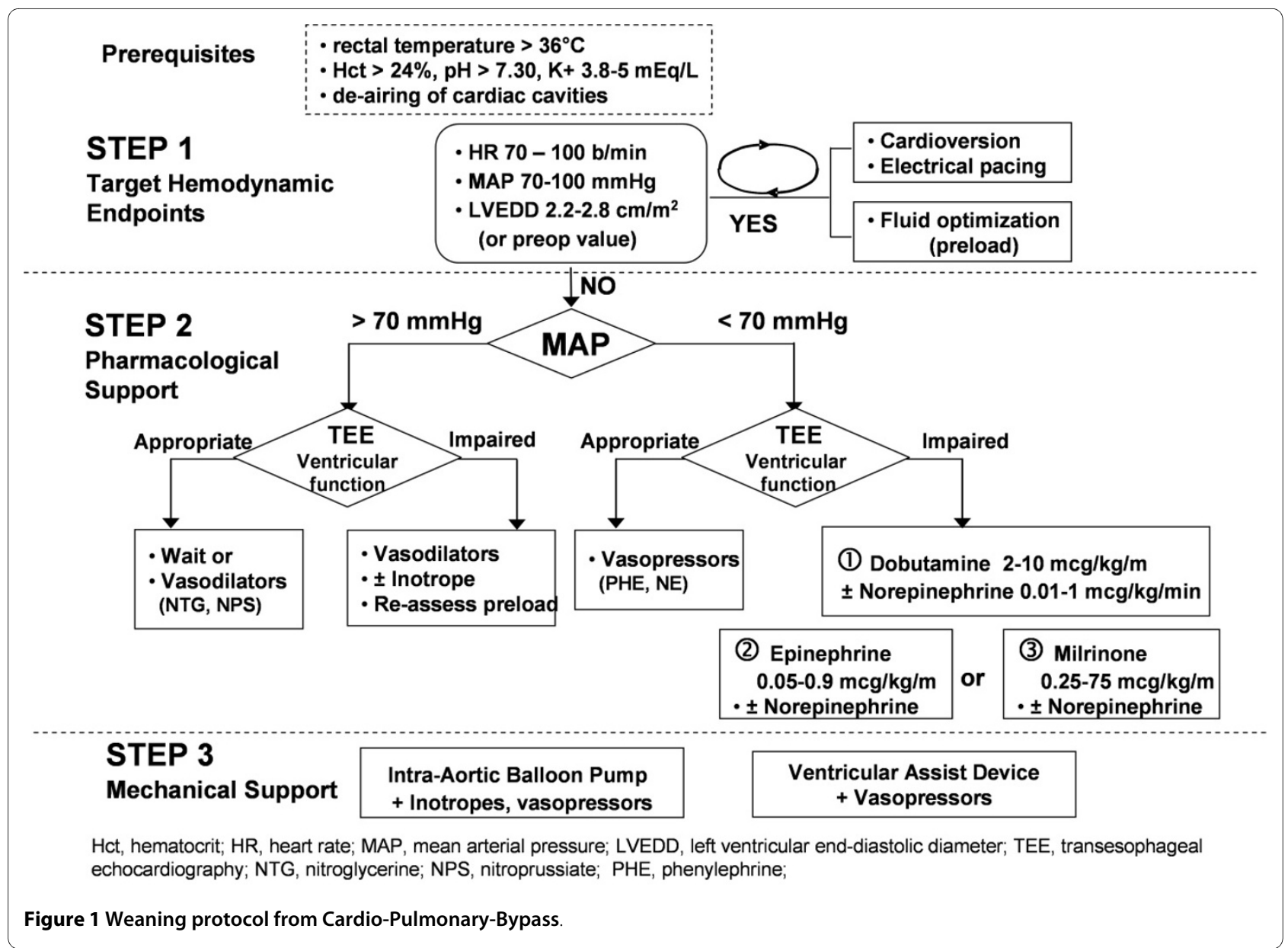

process and the attending anesthesiologist in charge of the patient was blinded to the diastolic measurements. Pulmonary artery catheters were inserted in patients receiving inotropic support at the admission on the Intensive Care Unit (ICU).

\section{Study endpoints}

The diagnostic criteria for post-CPB LV dysfunction was based on the need of inotropic support for at least two hours (dobutamine $\geq 5 \mathrm{mcg} / \mathrm{kg} / \mathrm{min}$, epinephrine $>0.05$ $\mathrm{mcg} / \mathrm{kg} / \mathrm{min}$, milrinone $>0.25 \mathrm{mcg} / \mathrm{kg} / \mathrm{min}$, norepinephrine $>0.02 \mathrm{mcg} / \mathrm{kg} / \mathrm{min})$ in the presence of low MAP $(<60$ $\mathrm{mmHg}$ ascertained by both invasive and noninvasive pressure monitors) and with persistent, new or worsening LV functional impairment (for example, FAC (fractional area change) $<40 \%$ ). Secondary outcome variables were any postoperative cardiac adverse event occurring in the ICU such as myocardial infarct (troponin-I $\geq 1.5$ $\mathrm{ng} / \mathrm{ml}$ associated with new $\mathrm{Q}$ waves or ST segment abnormalities on the ECG, or with coronary artery intervention), supra-ventricular or ventricular arrhythmias (requiring anti-arrhythmic drugs or electrical cardioversion) and low cardiac output syndrome (cardiac index
$<2.2 \mathrm{~L} / \mathrm{min} / \mathrm{m}^{2}$, need for inotropic and/or IABP support to maintain MAP $>65 \mathrm{mmHg}$ ).

\section{Measurements}

During primary hospitalization, data related to patient demographic information, comorbidities, current medications, intraoperative TEE examination, indexed effective orifice area [19], anesthetic and surgical management as well as postoperative cardiac outcome were prospectively collected on a case report form and entered in a dedicated database.

A comprehensive TEE examination was performed before CPB using two-dimensional, M-mode, pulsed Doppler and TDI to assess systolic and diastolic LV function. In the transgastric short axis view, posterior wall thickness (PWT), LV end-diastolic and end-systolic areas (EDA and ESA, respectively) were measured. FAC of the LV was computed as (LVEDA -LVESA)/LVEDA. From a mid-esophageal four-chamber view, peak early (E) and late (A) mitral inflow velocities, deceleration time (DT) and isovolumic relaxation time (IVRT) were derived from recordings obtained with the pulsed Doppler sample volume positioned at the tip of the mitral leaflets. Peak sys- 
tolic (S), diastolic (D) and atrial reversal velocities (Ar) were measured with the pulsed Doppler sample volume positioned within 1 to $2 \mathrm{~cm}$ of the left upper pulmonary vein. Thereafter, the TDI function was activated for recording early and late diastolic velocities of the mitral annulus ( $E^{\prime}$ and $A^{\prime}$, respectively) by positioning the $5-\mathrm{mm}$ sample volume within the septal and lateral insertion sites of the mitral leaflets to cover the longitudinal excursion of the mitral annulus. Finally, a color M-mode map was displayed from a mid-oesophageal four-chamber view, to obtain the longest column of flow from the mitral annulus to the apex. The M-mode cursor was aligned through the center, parallel to the transmitral inflow and a clear propagation wave front was obtained by adjusting the Nyquist limit and baseline shift. Vp was defined as the slope of the first aliasing velocity during early filling, measured from the mitral valve opening to $4 \mathrm{~cm}$ into the LV cavity.

Cardiac stroke volume was calculated as the flow surface area multiplied by the velocity time integral through the LV outflow tract obtained by pulsed wave Doppler. Cardiac index (CI) was calculated as the product of SV and HR divided by body surface area. All recorded values were averaged from three consecutive beats.

Poor systolic LV function was considered if the LV ejection was $<40 \%$ on the preoperative transthoracic echocardiographic examination. According to the working group of the European Association of Echocardiography and the American Society of Echocardiography, LV diastolic function was graded into four classes: normal (E/A $>0.8$, $\mathrm{DT}<200 \mathrm{~ms}$, and $\mathrm{E}^{\prime} / \mathrm{A}^{\prime}>1$ or S/D 1 to 1.5$)$, impaired relaxation $(\mathrm{E} / \mathrm{A}<0.8$, DT $>200 \mathrm{~ms}$, IVRT $\geq 100 \mathrm{~ms}$ and $\mathrm{E}^{\prime} / \mathrm{A}^{\prime}<1$ or $\mathrm{S} / \mathrm{D}>1.5$ ), pseudo-normalization (E/A = 1 to 2, $\mathrm{DT}=150$ to $200 \mathrm{~ms}$, and $\mathrm{E}^{\prime} / \mathrm{A}^{\prime}<1$ or $\left.\mathrm{S} / \mathrm{D}<1.2\right)$, and restrictive pattern (E/A $>2$, DT $<150 \mathrm{~ms}$ and $\mathrm{E}^{\prime} / \mathrm{A}^{\prime}<1$ or $\mathrm{S} /$ $\mathrm{D}<0.8)[19]$.

To test the intra- and interobserver variabilities, $\mathrm{E}$ and $A, E^{\prime}$ and $A^{\prime}$ as well as Vp were measured twice by two independent operators, in 10 randomly selected cases.

\section{Statistical analysis}

Perioperative clinical, surgical and echocardiographic characteristics of patients with and without post-CPB LV dysfunction were compared with the $\chi^{2}$ test for categorical variables (expressed in percentage) and the Student $t$ test (normal distribution) or Wilcoxon rank test (nonGaussian distribution) for continuous variables (all expressed as mean $\pm \mathrm{SD}$ ).

Variables that had a univariate probability value $<0.20$ or those judged to be clinically important were selected for inclusion in a logistic regression model by stepwise selection. To avoid multi-colinearity, only one variable was retained in a set of variables with a correlation coefficient greater than 0.5 . Independent predictors of LV dys- function and factor-adjusted odds ratios (ORs) with 95\% confidence interval (CI) were calculated. Model discrimination was evaluated by the area under the receiver-operator-characteristic (ROC) curve, and calibration was assessed with the Hosmer-Lemeshow goodness-of-fit statistic. Receiver operating characteristics (ROC) curves were constructed to determine the best cut-off of echocardiographic parameters (with $P<0.2$ ) to predict post-CPB LV dysfunction. All analyses were performed using SPSS software (version 14.0 for Microsoft Windows; SPSS, Chicago, IL, USA) and statistical significance was specified as a two-tailed type I error ( $P$ value) set below the 0.05 level.

\section{Results}

Over a three-year period, 108 high-risk patients underwent valve replacement for severe aortic stenosis and 14 were excluded since Doppler-derived pulmonary flow indices and TDI could not be obtained ( 9 and 11 patients, respectively). In the remaining 94 patients, all presented LV hypertrophy (PWT $>11 \mathrm{~mm}$ ), poor systolic LV function was found in $14 \%$ of patients $(\mathrm{n}=12)$ whereas diastolic dysfunction was diagnosed in $84 \%$ of patients $(\mathrm{n}=$ 89), all of whom had $\mathrm{Vp}<50 \mathrm{~cm} / \mathrm{s}$. Regarding echocardiographic measurements, intra-and interobserver variabilities were lowest for $\mathrm{Vp}$ and highest for $\mathrm{E}^{\prime}$ and $\mathrm{A}^{\prime}$ measurements (Table 1).

During weaning from CPB, LV dysfunction occurred in 38 patients $(40.4 \%)$. Inotropic support consisted in the administration of dobutamine $(5.6 \pm 2.7 \mathrm{mcg} / \mathrm{kg} / \mathrm{h}$, over $10 \pm 5$ hours $)$, epinephrine $(0.52 \pm 0.41 \mathrm{mcg} / \mathrm{kg} / \mathrm{h}$ over $6 \pm$ 3 hours $)$, norepinephrine $(0.08 \pm 0.04 \mathrm{mcg} / \mathrm{kg} / \mathrm{h}$ over $12 \pm$ 7 hours $)$ and/or milrinone $(0.27 \pm 0.14 \mathrm{mcg} / \mathrm{kg} / \mathrm{h}$ over $6 \pm$ 2 hours). Five patients were also treated with an IABP in combination with inotropes. As shown in Table 2, MAP and $\mathrm{CI}$ were significantly lower in patients with post- $\mathrm{CPB}$ LV dysfunction. Of the 31 preoperative and intraoperative variables subjected to univariate analysis, eight demonstrated a significant association with the occurrence of post-CPB LV dysfunction (Table 3). Patients with postCPB LV dysfunction were significantly older, they had lower LV ejection fraction, more severe grades of LV diastolic dysfunction, lower $\mathrm{Vp}$ as well as prolonged duration of $\mathrm{CPB}$ and aortic clamping.

Stepwise logistic regression analyses identified three independent predictors of LV dysfunction: age $(\mathrm{OR}=$ 1.11; $95 \% \mathrm{CI}, 1.01$ to 1.22$)$, aortic clamping time $(\mathrm{OR}=$ 1.04; $95 \% \mathrm{CI}, 1.00$ to 1.08$)$ and $\mathrm{Vp}(\mathrm{OR}=0.65$; $95 \% \mathrm{CI}$, 0.52 to 0.81 ). This multivariate model for predicting $\mathrm{LV}$ dysfunction was robust, with an area under the ROC curve of 0.96 ( $95 \%$ CI, 0.89 to 0.99 ) and a Hosmer-Lemeshow goodness-of-fit probability value of 0.49 indicating good model calibration and discrimination. Substitution of aortic clamping time for $\mathrm{CPB}$ time and diastolic classes 
Table 1: Intra- and interobserver characteristics

\begin{tabular}{llc}
\hline Characteristics & Intra-observer variability & Inter-observer variability \\
\hline E wave & & 8.7 \\
A wave & 7.8 & 9.4 \\
Deceleration time & 8.1 & 9.6 \\
PV S & 8.9 & 8.2 \\
PV D & 7.1 & 9.1 \\
E' wave lateral & 8.3 & 8.8 \\
A' wave lateral & 7.9 & 9.2 \\
E' wave septal & 8.1 & 11.6 \\
A' wave septal & 9.4 & 10.9 \\
Vp & 9.7 & 4.8 \\
\hline
\end{tabular}

PV S, peak systolic velocity of pulmonary venous flow; PV D, peak diastolic velocity of pulmonary venous flow; $E$, peak early mitral inflow; , late mitral inflow; DT, deceleration time; E' and A', early and late diastolic annular velocities, $\mathrm{Vp}$, transmitral flow velocity

(1 to 4) for $\mathrm{Vp}$, did not improve the area under the ROC curve. There was no evidence that additional covariates would improve the model $(P=0.21$ by the Wald link specification test).

As shown in Figure 2, the best cut-off value for $\mathrm{Vp}$ to predict LV dysfunction was $40 \mathrm{~cm} / \mathrm{s}$ as it maximized both sensitivity (73\%; $95 \% \mathrm{CI}, 55 \%$ to $87 \%$ ) and specificity (96\%; 95\% CI, 87\% to $99 \%$ ).

The expected mortality of the whole cohort was $22 \%$ whereas the observed mortality was only $10.6 \%$. As shown in Table 4, compared with patients without postCPB LV dysfunction, those experiencing LV dysfunction presented higher in-hospital mortality $(18.4 \%$ vs. $3.6 \%, P$ $=0.044)$ and an increased incidence of serious cardiac events ( 81.6 vs. $28.6 \%, P<0.001)$. These patients also required prolonged mechanical ventilation and longer stay in the ICU and in the hospital.

The incidence of LV dysfunction and cardiac complications increased significantly with the severity of diastolic dysfunction, particularly in patients with a restrictive filling pattern and those with Vp less than $40 \mathrm{~cm} / \mathrm{s}$ (Figure 3). Noteworthy, LV dysfunction was observed in 28 out of 30 patients $(90 \%)$ with low $\mathrm{Vp}(\leq 40 \mathrm{~cm} / \mathrm{sec})$ as opposed to 7 out of 64 patients with normal-to-high $\mathrm{Vp}$.

\section{Discussion}

In this prospective study, $40 \%$ of high-risk patients undergoing aortic valve replacement required inotropic sup-

Table 2: Hemodynamic in patients with and without post-CPB left ventricular dysfunction

\begin{tabular}{|c|c|c|c|}
\hline & No LV dysfunction $(n=56)$ & With LV dysfunction $(n=38)$ & Pvalue \\
\hline \multicolumn{4}{|l|}{ Mean Arterial Pressure, mmHg } \\
\hline Before CPB (10 minutes) & $93(12)$ & $90(15)$ & 0.847 \\
\hline After CPB (10 minutes) & $82(14)$ & $68(16)^{*}$ & 0.012 \\
\hline \multicolumn{4}{|l|}{ Heart Rate, b/min } \\
\hline Before CPB (10 minutes) & $70(8)$ & $73(9)$ & 0.912 \\
\hline After CPB (10 minutes) & $78(13)$ & $82(14)$ & 0.634 \\
\hline \multicolumn{4}{|c|}{ Central Venous Pressure, $\mathrm{cm} \mathrm{H}_{2} \mathrm{O}$} \\
\hline Before CPB (10 minutes) & $6(3)$ & $7(4)$ & 0.879 \\
\hline After CPB (10 minutes) & $8(4)$ & $9(5)$ & 0.953 \\
\hline \multicolumn{4}{|l|}{ Cardiac Index, L/min/m² } \\
\hline Before CPB (10 minutes) & $2.4(1.0)$ & $2.2(1.3)$ & 0.597 \\
\hline After CPB (10 minutes) & $3.6(1.3)$ & $2.1(0.9)^{*}$ & $<0.001$ \\
\hline
\end{tabular}

$\mathrm{LV}$, left ventricular; CPB, cardiopulmonary bypass.

${ }^{*} P<0.05$, between the two groups; $\times 2$ test with Yates correction or unpaired Student $t$ test. 
Table 3: Distribution of perioperative variables according to the presence of post-CPB left ventricular dysfunction

\begin{tabular}{|c|c|c|c|}
\hline & No LV dysfunction $(n=56)$ & With LV dysfunction $(n=38)$ & $P$ value \\
\hline \multicolumn{4}{|l|}{ Preoperative clinical and biological variables } \\
\hline Age (y) & $66(9)$ & $74(10)$ & 0.004 \\
\hline Male Gender (\%) & 61.8 & 66.7 & 0.288 \\
\hline Body Mass Index (kg/m2) & $28(5)$ & $27(6)$ & 0.281 \\
\hline Hypertension (\%) & 85.1 & 82.3 & 0.654 \\
\hline Diabetes Mellitus (\%) & 30.9 & 27.5 & 0.745 \\
\hline Coronary Artery Disease (\%) & 29.1 & 38.5 & 0.412 \\
\hline Peripheral Vascular Disease (\%) & 12.1 & 10.9 & 0.511 \\
\hline Dyslipemia (\%) & 71.8 & 54.5 & 0.098 \\
\hline Renal Insufficiency1 (\%) & 3.6 & 5.2 & 0.532 \\
\hline Anemia2 (\%) & 7.1 & 10.1 & 0.789 \\
\hline Beta-blockers (\%) & 49.1 & 61.5 & 0.295 \\
\hline ACE Inhibitors or All antagonists (\%) & 20.1 & 35.9 & 0.352 \\
\hline Calcium channel antagonists (\%) & 23.6 & 33.3 & 0.101 \\
\hline Diuretics (\%) & 21.9 & 17.9 & 0.796 \\
\hline Nitrate (\%) & 12.7 & 17.9 & 0.562 \\
\hline LV Ejection Fraction (\%) & $56(8)$ & $49(11)$ & 0.001 \\
\hline Parsonnet score (u) & $15(9)$ & $21(9)$ & 0.001 \\
\hline \multicolumn{4}{|l|}{ Intraoperative echocardiographic data } \\
\hline LV Mass Index (g/m2) & $135(34)$ & $140(29)$ & 0.188 \\
\hline LV Fractional Area Changes (\%) & $54(14)$ & $46(14)$ & 0.015 \\
\hline LV Septal Thickness (mm) & $16(3)$ & $17(4)$ & 0.899 \\
\hline Transmitral E/A ratio & $1.2(0.6)$ & $1.3(0.7)$ & 0.415 \\
\hline Deceleration Time (ms) & $181(81)$ & $158(65)$ & 0.173 \\
\hline Isovolemic Relaxation Time (ms) & $108(30)$ & $106(32)$ & 0.897 \\
\hline PV S/D ratio & $1.2(0.4)$ & $1.1(0.5)$ & 0.067 \\
\hline PV Ar (ms) & $14(9)$ & $16(7)$ & 0.198 \\
\hline$E^{\prime} / A^{\prime}$ lateral & $1.0(0.5)$ & $0.9(0.5)$ & 0.736 \\
\hline E'/A' septal & $1.0(0.4)$ & $1.0(0.6)$ & 0.716 \\
\hline $\mathrm{Vp}(\mathrm{cm} / \mathrm{s})$ & $53(11)$ & $37(7)$ & $<0.001$ \\
\hline Diastolic Functional Class & & & $<0.001$ \\
\hline Normal (\%) & 26.8 & 0 & \\
\hline Impaired Relaxation (\%) & 50.0 & 34.2 & \\
\hline Pseudo-normalization (\%) & 23.2 & 42.1 & \\
\hline Restrictive pattern (\%) & 0.0 & 23.7 & \\
\hline Surgical variables & 11 & 16 & \\
\hline Type of Procedure (\%) & & & 0.280 \\
\hline Isolated Valve Replacement & 65.9 & 51.1 & \\
\hline Associated Coronary Artery Bypass & 21.6 & 34.1 & \\
\hline
\end{tabular}


Table 3: Distribution of perioperative variables according to the presence of post-CPB left ventricular dysfunction

\begin{tabular}{lccc}
\hline \multicolumn{1}{c}{ Associated Aortic Root Replacement } & 12.5 & 14.8 & \\
Aortic Clamping Time (minutes) & $77(28)$ & $98(40)$ & 0.010 \\
Cardiopulmonary Bypass Time (minutes) & $101(33)$ & $135(57)$ & 0.004 \\
Indexed Effective Orifice Area & $1.05(0.11)$ & $0.98(0.13)$ & 0.634 \\
\hline
\end{tabular}

$\mathrm{LV}$, left ventricular; $\mathrm{CPB}$, cardiopulmonary bypass.

${ }^{*} P<0.05$, between the two groups; $X^{2}$ test with Yates correction or unpaired Student $t$ test.

$\mathrm{LV}$, left ventricule; ACE, angiotensin converting enzyme; All, angiotensin II; PV Ar, pulmonary vein atrial reversal velocity; PV S/D, ratio of peak systolic to diastolic pulmonary vein flow velocities; $E^{\prime} / A^{\prime}$, ratio of early to late diastolic velocities of the mitral annulus determined by tissue Doppler imaging.

${ }^{1}$ Renal insufficency defined as creatinine clearance $<10 \mathrm{ml} /$ minute.

${ }^{2}$ Anemia defined as Hemoglobin $<110 \mathrm{~g} / \mathrm{L}$ in female and $<120 \mathrm{~g} / \mathrm{L}$ in male.

port and/or an intraortic balloon pump for weaning from $\mathrm{CPB}$. Advanced age, preoperative LV diastolic dysfunction and prolonged aortic clamping time were identified as independent risk factors of post-CPB LV dysfunction. Among the echocardiographic markers of LV diastolic dysfunction, the transmitral flow propagation wave $(\mathrm{Vp})$ was found superior in terms of prognostic value and reliability. Below a cut-off value of $40 \mathrm{~cm} / \mathrm{s}, 90 \%$ of patients required inotropic support after weaning from $\mathrm{CPB}$ as opposed to only $11 \%$ among those with preoperative $\mathrm{Vp}$ $>40 \mathrm{~cm} / \mathrm{s}$.

The anesthetic and surgical techniques were all standardized and protocol-driven hemodynamic treatments were based on information gathered from pressure monitors and TEE examination. In contrast to previous large cohort studies, we focused on aortic valvular patients with an expected operative mortality $\geq 9 \%$ based on the

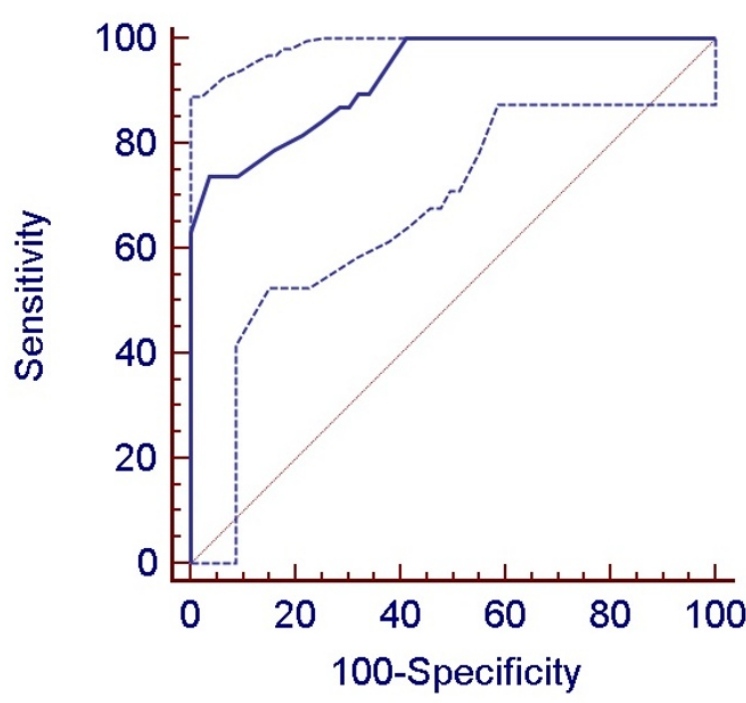

Figure $\mathbf{2}$ Receiver operating characteristic (ROC) curves assessing the association of transmitral propagation velocities $(\mathrm{Vp})$ with post-cardiopulmonary bypass left ventricular dysfunction (mean and $95 \%$ coinfidence limits).
Bernstein-Parsonnet algorithm [20]. The higher operative risk profile was mainly related to hypertension $(84 \%$ of patients), advanced age ( $62 \% \geq 70$ years) hyperlipidemia $(62 \%)$ and diabetus mellitus (28\%), all factors known to participate in the development of LV hypertrophy and diastolic LV dysfunction [21].

Predictors of LV dysfunction after aortic valvular replacement have been investigated in four other studies which largely differ in their case-mix, hemodynamic treatments and criteria to define the main study endpoint [6-8,22]. In these cohort studies, inotropic therapy varied from $4 \%$ to $52 \%$ and was mainly related to advanced age, congestive heart failure, low LV ejection fraction, elevated LV end-diastolic pressure and prolonged aortic cross-clamping time. Interestingly, we found that patients with post-CPB LV dysfunction experienced higher plasma levels of troponin and a two-to-three fold increase in postoperative cardiac complications. Consistent with these data, Müller et al. reported a higher 30day mortality rate among patients receiving inotropic drugs following cardiac surgery [22].

Our study is the first investigation assessing the prognostic implication of echocardiographic markers in addition to clinical and surgical variables in patients undergoing aortic valve replacement. Based on standard Doppler-derived measurements, more than $80 \%$ of patients presented LV diastolic dysfunction and, all of them had $\mathrm{Vp}<50 \mathrm{~cm} / \mathrm{s}$. This was consistent with previous reports identifying abnormal LV relaxation and filling patterns in more than $50 \%$ of elderly, in patients with aortic stenosis and those undergoing coronary artery bypass surgery $[23,24]$. As reported in longitudinal populationbased studies, LV diastolic dysfunction often precedes the development of LV systolic impairment, conveying a poor prognosis, particularly after myocardial infarct, in congestive heart failure and in cardiac amyloidosis [25-27].

Preoperative LV diastolic dysfunction associated with myocardial hypertrophic and fibrotic changes could predispose patients to LV dysfunction during weaning from $\mathrm{CPB}$ for several reasons. First, patients with enlarged car- 


\begin{tabular}{|c|c|c|c|}
\hline & $\begin{array}{l}\text { No post-CPB LV dysfunction } \\
\qquad(n=56)\end{array}$ & $\begin{array}{l}\text { With post-CPB LV } \\
\text { dysfunction }(n=38)\end{array}$ & $P$ value \\
\hline In-Hospital Mortality (\%) & 3.6 & $18.4^{*}$ & 0.044 \\
\hline \multicolumn{4}{|l|}{ Adverse Cardiac events (\%) } \\
\hline Myocardial Infarct (\%) & 0 & $13.2^{*}$ & 0.022 \\
\hline Arrhythmia's (\%) & 19.6 & $50^{*}$ & 0.029 \\
\hline Low Cardiac Output (\%) & 1.8 & $60.5^{*}$ & $<0.001$ \\
\hline Wound infection (\%) & 3.6 & 5.3 & 0.665 \\
\hline Pneumonia (\%) & 3.6 & 7.9 & 0.368 \\
\hline Re-operation (\%) & 8.9 & 5.3 & 0.773 \\
\hline Duration of Mechanical Ventilation (h) & $9(7)$ & $38(28)^{*}$ & 0.032 \\
\hline Peak Serum Troponin (ng/L) & $1.7(1.2)$ & $12.3(9.2)^{*}$ & 0.026 \\
\hline Peak Serum Creatinin (mg/L) & $88(24)$ & $102(46)$ & 0.092 \\
\hline Duration of stay in ICU (d) & $3.1(1.5)$ & $6.9(5.5)^{*}$ & $<0.001$ \\
\hline Duration of stay in Hospital (d) & $10(3)$ & $14(7)^{*}$ & 0.022 \\
\hline
\end{tabular}

$\mathrm{LV}$, left ventricular; CPB, cardiopulmonary bypass.

${ }^{*} P<0.05$, between the two groups; $X^{2}$ test with Yates correction or unpaired Student $t$ test.

diac muscular mass and reduced capillary density are prone to develop ischemic lesions due to suboptimal delivery of the cardioplegic solution particularly after prolonged aortic cross-clamping time $[28,29]$. Second, accelerated apoptosis of hypertrophied cardiomyocytes may further decrease mechanical cardiac efficiency and has been shown to correlate with increased release of troponin following aortic valve surgery [30,31]. Third, LV diastolic dysfunction often coexists with latent or patent alterations in systolic LV function that corresponds to the clinical syndrome of congestive heart failure and the functional states of elevated LV end-diastolic pressure or low $L V$ ejection fraction which are all considered strong predictors of LV dysfunction, cardiac complications and mortality after cardiac surgery $[2,3,5-8,32]$.

Although Doppler-derived mitral inflow and pulmonary venous flow measurements as well as TDI currently provide the cornerstones of the assessment of LV diastolic function, their practical application in the operating room may be hampered by difficulties in recording and measuring each of these parameters within a short time in anesthetized cardiac patients. In addition, most of these echo-Doppler parameters are highly influenced by age, heart rate and loading conditions [33]. Therefore, dynamic tests such as the Valsalva manoeuvre are necessary to unmask impaired LV relaxation and to distinguish pseudo-normalization patterns. In our experience, these measurements were less reproducible (intra- and interobserver variabilities ranging from $7 \%$ to $10 \%$ and $8 \%$ to $12 \%$, respectively) and could not be obtained in $13 \%$ of patients. In addition, extensive calcifications of the aortic valve likely restrain the downward excursion of the mitral annulus resulting in low peak annular velocities (E') which underestimates LV longitudinal relaxation. Likewise, the success rate of Doppler-derived pulmonary flow measurements has been reported within a wide range (37\% to $99 \%)$ and with considerable inter-reader variability (3\% to $21 \%)[34,35]$.

In agreement with other studies, we could easily determine $\mathrm{Vp}$ in all patients without post-acquisition manipulation and with minimal inter-and intraoperator variability $(<5 \%)[34,36]$. Basically, $\mathrm{Vp}$ reflects the spatiotemporal distribution of early diastolic blood flow generated by atrio-ventricular pressure gradients and vorticity resulting from shear between inflowing and stationary blood in the LV. A significant negative correlation has been demonstrated between $\mathrm{Vp}$ and the gold standard parameter of LV diastolic function, the time constant of relaxation $(\tau)$ [35]. Besides simplicity and reproductibility, $\mathrm{Vp}$ is less dependent on loading conditions and heart rate changes. Consistent with previous studies [24,37,38], below a threshold value of $50 \mathrm{~cm} / \mathrm{sec}$, Vp reliably detected all grades of diastolic dysfunction. In addition, analysis of ROC curves indicated that a cut-off value of $40 \mathrm{~cm} / \mathrm{sec}$ was helpful to discriminate patients experiencing LV dysfunction after weaning from $\mathrm{CPB}$ that was also paralleled by an increased incidence of adverse cardiac events in the ICU. Likewise, Matyal et al. [39] confirmed the importance of LV diastolic dysfunction for risk stratification in vascular surgery. Below a $\mathrm{Vp}$ threshold of $45 \mathrm{~cm} / \mathrm{sec}$, 
(a)

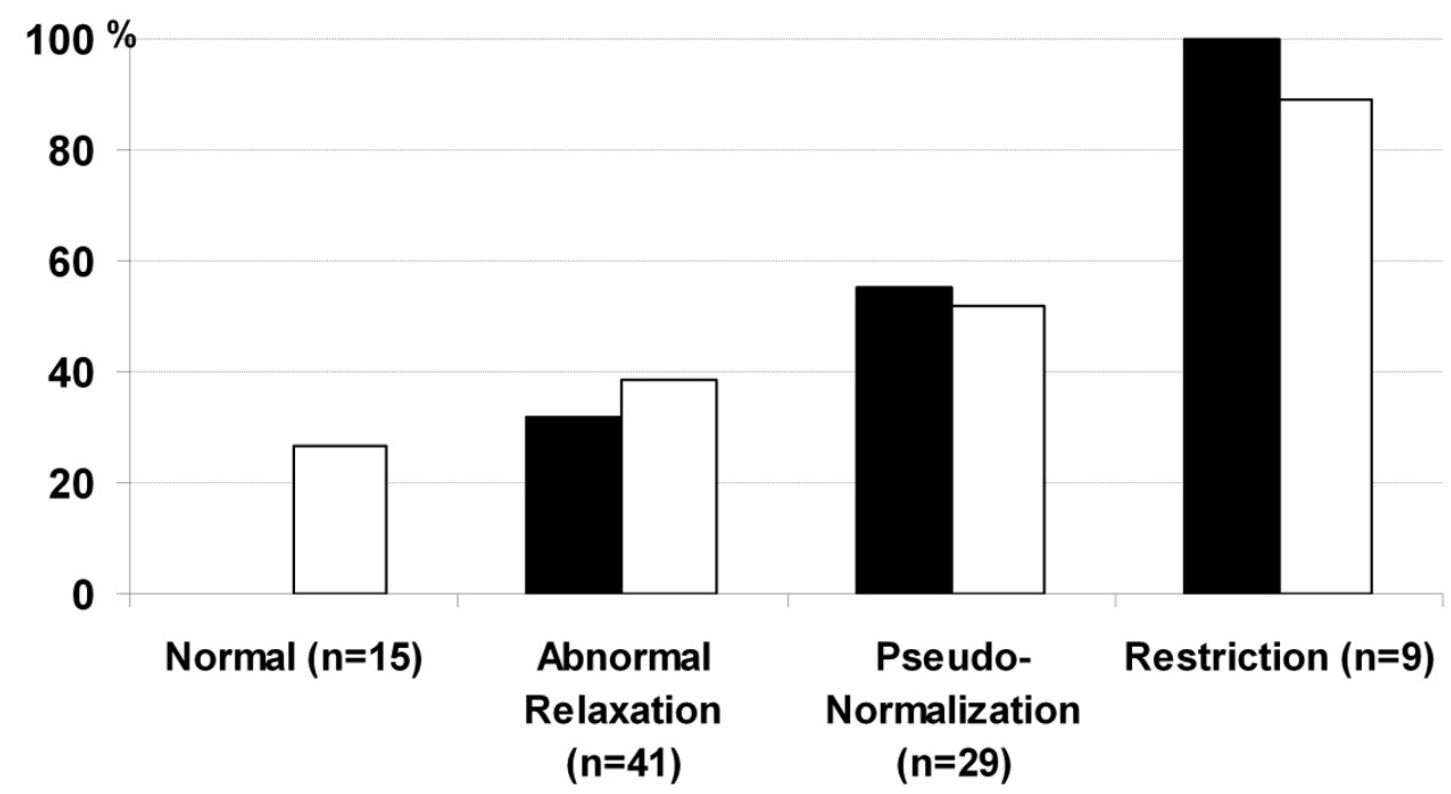

(b)

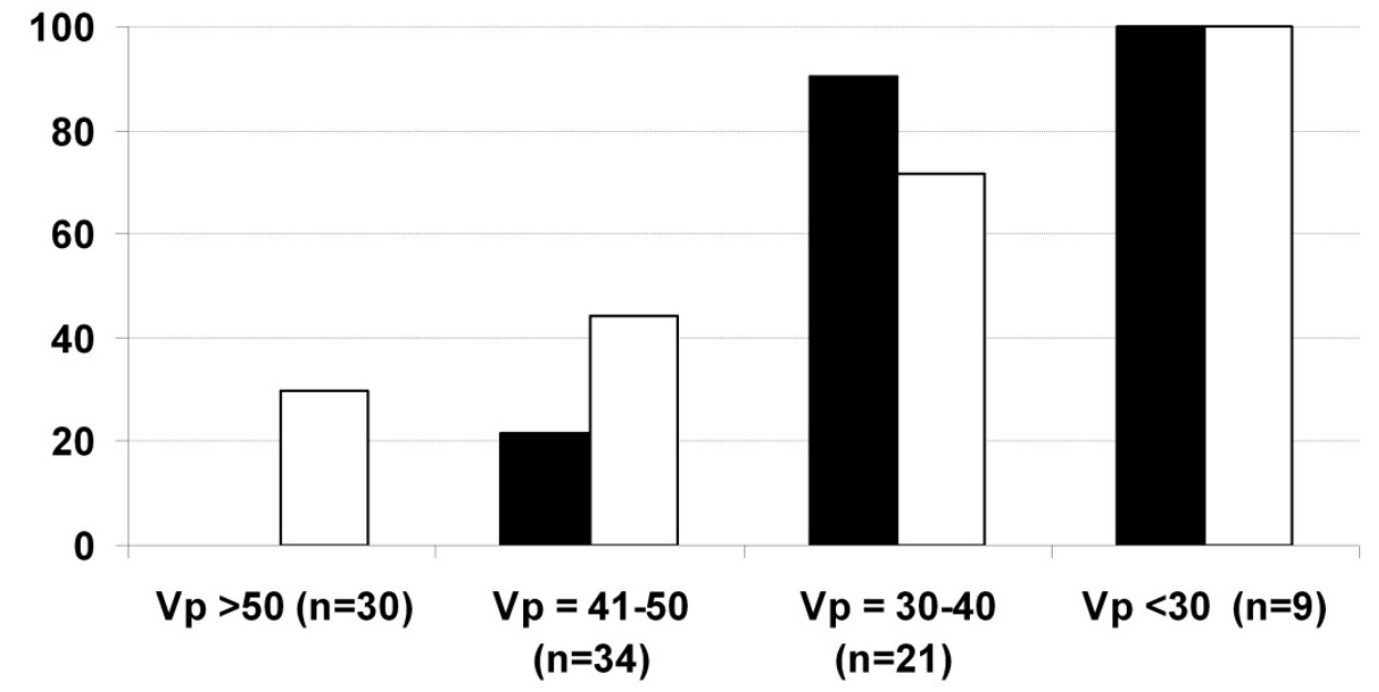

Figure 3 Incidence of post-cardiopulmonary bypass left ventricular dysfunction (black square) and postoperative cardiac complications (open square. Myocardial infarct, arrhythmias and/or low cardiac output syndrome) in relation with the severity of left ventricular diastolic dysfunction are expressed by standard classification (a) and by transmitral flow propagation velocity (Vp) (b).

patients were twice as likely to experience at least one postoperative adverse events than patients with $\mathrm{Vp}>45$ $\mathrm{cm}$. Taken together, these data suggest that, in the perioperative settings where hemodynamic conditions are changing often rapidly, $\mathrm{Vp}$ is better suited to evaluate $\mathrm{LV}$ diastolic function than the traditional echo-Doppler parameters.
We are mindful of several limitations. First, being conducted in a single centre with a relatively small population sample focusing mainly on LV function, this observational study requires further validation in a larger group of patients with a combined assessment of left and right ventricular function. Patients with arrhythmias and pulmonary hypertension were excluded from the study 
and the low prevalence of systolic LV failure, anemia and renal failure precluded any conclusion regarding these potential risk factors (type II error, false negative results). Second, Vp might underestimate the severity of diastolic dysfunction in cases presenting LV chamber dilation due to swirlings of the inflow along the LV wall $[19,34]$. Since less than $15 \%$ of our patients presented low LV ejection, we presume that low Vp values correctly reflect impairments in LV relaxation and filling. Third, although increased LV wall thickness was documented in all patients, we did not examine the influence of LV geometry (for example, excentric or concentric hypertrophy, remodelling) and plasma biomarkers of cardiac distension (for example, brain natriuretic peptides (BNP) on LV diastolic function. Interestingly, several reports have stressed the negative impact of concentric LV geometries (with or without enlarged cardiac mass) and of elevated BNP levels on in-hospital mortality and early cardiac complications [40-42].

\section{Conclusions}

This study provides the first evidence that diastolic dysfunction as defined by $\mathrm{Vp}<40 \mathrm{~cm} / \mathrm{s}$, in addition to advanced age and prolonged ischemic time, identifies patients at risk of $\mathrm{LV}$ dysfunction after valvular aortic surgery. Clinicians should anticipate a greater impact of perioperative TEE to identify high-risk cardiac patients while improving fluid and inotropic/lusitropic drug treatments. The association of preoperative diastolic dysfunction with adverse cardiac outcome begs the question as to whether trials of specific perioperative strategies to improve LV relaxation and filling patterns should be considered in patients undergoing aortic valve surgery.

\section{Key messages}

- Advanced age, preoperative LV diastolic dysfunction and prolonged aortic clamping time are significant predictors of $\mathrm{LV}$ dysfunction following $\mathrm{CPB}$ requiring inotropic support in patients undergoing valve replacement for aortic stenosis.

- Among several echocardiographic parameters, transmitral flow propagation velocity $(\mathrm{Vp})$ less than $40 \mathrm{~cm} / \mathrm{sec}$ best identified patients at higher risk of LV dysfunction after $\mathrm{CPB}$ and was associated with more frequent cardiac complications in the ICU.

\footnotetext{
Abbreviations

BNP: brain natriuretic peptides; Cl: confidence interval; CPB: cardiopulmonary bypass; DT: deceleration time; E' and A': early and late diastolic velocities of the mitral annulus; EDA: end-diastolic area; ESA: end-systolic area; FAC: fractional area change; IABP: intra-aortic balloon pump; IVRT: isovolumic relaxation time; LV: left ventricular; MAP: mean arterial pressure; ORs: odds ratios; PWT: posterior wall thickness; ROC: receiver-operator-characteristic; S: D and Ar: peak systolic, diastolic and atrial reversal velocities of pulmonary venous flow; TDI: tissue Doppler imaging; TEE: transoesophageal echocardiography; Vp: transmitral flow propagation velocity.
}

Competing interests

The authors declare that they have no competing interests.

\section{Authors' contributions}

$M L$ and JD participated in the study design, data analysis, interpretation of the data as well as the writing of the manuscript. JD, VC and CI participated in data collection, literature search and data interpretation. AK, TC, TT and MC participated in revising the bibliography, and correcting and editing the manuscript. All the authors have read and approved the final manuscript.

\section{Acknowledgements}

The Lancardis Foundation in Sion (Switzerland) granted partial support for this study. No other sources have influenced the study design, data analysis or decision to submit the manuscript for publication.

\section{Author Details}

${ }^{1}$ Faculty of Medicine (University of Geneva) and Department of Anaesthesiology, Pharmacology and Intensive Care, University Hospital, rue Gabrielle-Perret-Gentil, CH-1211 Geneva 14, Switzerland, 2Department of Cardiovascular Surgery, University Hospital, rue Gabrielle-Perret-Gentil, CH1211 Geneva 14, Switzerland and ${ }^{3}$ Departement of Anesthesia and Critical Care, Cardiocentro Ticino, via Tesserete 48, CH- 6900 Lugano, Switzerland

Received: 1 September 2009 Revised: 20 November 2009 Accepted: 3 June 2010 Published: 3 June 2010

\section{References}

1. Wendt D, Osswald BR, Kayser K, Thielmann M, Tossios P, Massoudy P, Kamler M, Jakob H: Society of Thoracic Surgeons score is superior to the EuroSCORE determining mortality in high risk patients undergoing isolated aortic valve replacement. Ann Thorac Surg 2009, 88:468-474

2. Hannan EL, Samadashvili Z, Lahey SJ, Smith CR, Culliford AT, Higgins RS, Gold JP, Jones RH: Aortic valve replacement for patients with severe aortic stenosis: risk factors and their impact on 30-month mortality. Ann Thorac Surg 2009, 87:1741-1749.

3. Brown JM, O'Brien SM, Wu C, Sikora JA, Griffith BP, Gammie JS: Isolated aortic valve replacement in North America comprising 108,687 patients in 10 years: changes in risks, valve types, and outcomes in the Society of Thoracic Surgeons National Database. J Thorac Cardiovasc Surg 2009, 137:82-90.

4. Kastrup M, Markewitz A, Spies C, Carl M, Erb J, Grosse J, Schirmer U: Current practice of hemodynamic monitoring and vasopressor and inotropic therapy in post-operative cardiac surgery patients in Germany: results from a postal survey. Acta Anaesthesio/ Scand 2007 51:347-358.

5. Vanky FB, Hakanson E, Tamas E, Svedjeholm R: Risk factors for postoperative heart failure in patients operated on for aortic stenosis. Ann Thorac Surg 2006, 81:1297-1304.

6. Maganti MD, Rao V, Borger MA, Ivanov J, David TE: Predictors of low cardiac output syndrome after isolated aortic valve surgery. Circulation 2005, 112:|448-1452

7. Butterworth JF, Legault C, Royster RL, Hammon JW Jr: Factors that predict the use of positive inotropic drug support after cardiac valve surgery. Anesth Analg 1998, 86:461-467.

8. Ahmed I, House CM, Nelson WB: Predictors of inotrope use in patients undergoing concomitant coronary artery bypass graft (CABG) and aortic valve replacement (AVR) surgeries at separation from cardiopulmonary bypass (CPB). J Cardiothorac Surg 2009, 4:24

9. Rao V, Ivanov J, Weisel RD, Ikonomidis JS, Christakis GT, David TE: Predictors of low cardiac output syndrome after coronary artery bypass. J Thorac Cardiovasc Surg 1996, 112:38-51

10. Royster RL, Butterworth JF, Prough DS, Johnston WE, Thomas JL, Hogan PE, Case LD, Gravlee GP: Preoperative and intraoperative predictors of inotropic support and long-term outcome in patients having coronary artery bypass grafting. Anesth Analg 1991, 72:729-736.

11. McKinlay KH, Schinderle DB, Swaminathan M, Podgoreanu MV, Milano CA, Messier RH, El-Moalem H, Newman MF, Clements FM, Mathew JP: Predictors of inotrope use during separation from cardiopulmonary bypass. J Cardiothorac Vasc Anesth 2004, 18:404-408.

12. Denault AY, Couture P, Buithieu J, Haddad F, Carrier M, Babin D, Levesque S, Tardif JC: Left and right ventricular diastolic dysfunction as predictors 
of difficult separation from cardiopulmonary bypass. Can J Anaesth 2006, 53:1020-1029.

13. Bernard F, Denault A, Babin D, Goyer C, Couture P, Couturier A, Buithieu J: Diastolic dysfunction is predictive of difficult weaning from cardiopulmonary bypass. Anesth Analg 2001, 92:291-298.

14. Nakagawa D, Suwa M, Ito T, Kono T, Kitaura Y: Postoperative outcome in aortic stenosis with diastolic heart failure compared to one with depressed systolic function. Int Heart J 2007, 48:79-86.

15. Dewey TM, Brown D, Ryan WH, Herbert MA, Prince SL, Mack MJ: Reliability of risk algorithms in predicting early and late operative outcomes in high-risk patients undergoing aortic valve replacement. J Thorac Cardiovasc Surg 2008, 135:180-187.

16. Bruch C, Stypmann J, Grude M, Gradaus R, Breithardt G, Wichter T: Tissue Doppler imaging in patients with moderate to severe aortic valve stenosis: clinical usefulness and diagnostic accuracy. Am Heart J 2004, 148:696-702.

17. Oh JK, Hatle L, Tajik AJ, Little WC: Diastolic heart failure can be diagnosed by comprehensive two-dimensional and Doppler echocardiography. J Am Coll Cardiol 2006, 47:500-506.

18. Gabrielle F, Roques F, Michel P, Bernard A, de Vicentis C, Roques X, Brenot $R$, Baudet $E$, David M: Is the Parsonnet's score a good predictive score of mortality in adult cardiac surgery: assessment by a French multicentre study. Eur J Cardiothorac Surg 1997, 11:406-414.

19. Nagueh SF, Appleton CP, Gillebert TC, Marino PN, Oh JK, Smiseth OA, Waggoner AD, Flachskampf FA, Pellikka PA, Evangelisa A: Recommendations for the evaluation of left ventricular diastolic function by echocardiography. Eur J Echocardiogr 2009, 10:165-193.

20. Berman M, Stamler A, Sahar G, Georghiou GP, Sharoni E, Brauner R, Medalion B, Vidne BA, Kogan A: Validation of the 2000 BernsteinParsonnet score versus the EuroSCORE as a prognostic tool in cardiac surgery. Ann Thorac Surg 2006, 81:537-540.

21. Ruilope LM, Schmieder RE: Left ventricular hypertrophy and clinical outcomes in hypertensive patients. Am J Hypertens 2008, 21:500-508.

22. Muller M, Junger A, Brau M, Kwapisz MM, Schindler E, Akinturk H, Benson $M$, Hempelmann G: Incidence and risk calculation of inotropic support in patients undergoing cardiac surgery with cardiopulmonary bypass using an automated anaesthesia record-keeping system. Br J Anaesth 2002, 89:398-404.

23. Phillip B, Pastor D, Bellows W, Leung JM: The prevalence of preoperative diastolic filling abnormalities in geriatric surgical patients. Anesth Analg 2003, 97:1214-1221.

24. Djaiani GN, McCreath BJ, Ti LK, Mackensen BG, Podgoreanu M, PhillipsBute B, Mathew JP: Mitral flow propagation velocity identifies patients with abnormal diastolic function during coronary artery bypass graft surgery. Anesth Analg 2002, 95:524-530. table of contents

25. Whalley GA, Gamble GD, Doughty RN: Restrictive diastolic filling predicts death after acute myocardial infarction: systematic review and meta-analysis of prospective studies. Heart 2006, 92:1588-1594.

26. Persson H, Lonn E, Edner M, Baruch L, Lang CC, Morton JJ, Ostergren J, McKelvie RS: Diastolic dysfunction in heart failure with preserved systolic function: need for objective evidence:results from the CHARM Echocardiographic Substudy-CHARMES. J Am Coll Cardiol 2007, 49:687-694

27. Badano LP, Albanese MC, De Biaggio P, Rozbowsky P, Miani D, Fresco C, Fioretti PM: Prevalence, clinical characteristics, quality of life, and prognosis of patients with congestive heart failure and isolated left ventricular diastolic dysfunction. J Am Soc Echocardiogr 2004, 17:253-261

28. Natsuaki M, Itoh T, Okazaki Y, Rikitake K, Ohtubo S, Furukawa K: Risk factors associated with perioperative myocardial damage in patients with severe aortic stenosis. J Cardiovasc Surg (Torino) 2004, 45:271-277.

29. Ascione R, Caputo M, Gomes WJ, Lotto AA, Bryan AJ, Angelini GD, Suleiman MS: Myocardial injury in hypertrophic hearts of patients undergoing aortic valve surgery using cold or warm blood cardioplegia. Eur J Cardiothorac Surg 2002, 21:440-446.

30. Laine H, Katoh C, Luotolahti M, Yki-Jarvinen H, Kantola I, Jula A, Takala TO, Ruotsalainen U, lida H, Haaparanta M, Nuutila P, Knuuti J: Myocardial oxygen consumption is unchanged but efficiency is reduced in patients with essential hypertension and left ventricular hypertrophy. Circulation 1999, 100:2425-2430.

31. Gaudino M, Anselmi A, Abbate A, Galiuto L, Luciani N, Glieca F, Possati G Myocardial apoptosis predicts postoperative course after aortic valve replacement in patients with severe left ventricular hypertrophy. $J$ Heart Valve Dis 2007, 16:344-348.

32. Salem R, Denault AY, Couture P, Belisle S, Fortier A, Guertin MC, Carrier M, Martineau R: Left ventricular end-diastolic pressure is a predictor of mortality in cardiac surgery independently of left ventricular ejection fraction. Br J Anaesth 2006, 97:292-297.

33. Khouri SJ, Maly GT, Suh DD, Walsh TE: A practical approach to the echocardiographic evaluation of diastolic function. JAm Soc Echocardiogr 2004, 17:290-297.

34. Bess RL, Khan S, Rosman HS, Cohen GI, Allebban Z, Gardin JM: Technical aspects of diastology: why mitral inflow and tissue Doppler imaging are the preferred parameters? Echocardiography 2006, 23:332-339.

35. Masuyama T, Nagano R, Nariyama K, Lee JM, Yamamoto K, Naito J, Mano T, Kondo H, Hori M, Kamada T: Transthoracic Doppler echocardiographic measurements of pulmonary venous flow velocity patterns: comparison with transesophageal measurements. JAm SoC Echocardiogr 1995, 8:61-69

36. Palmieri V, Arezzi E, Sabatella M, Celentano A: Interstudy reproducibility of parameters of left ventricular diastolic function: a Doppler echocardiography study. J Am SOC Echocardiogr 2003, 16:1128-1135.

37. Mahmood F, Matyal R, Subramaniam B, Mitchell J, Pomposelli F, Lerner AB, Maslow A, Hess PM: Transmitral flow propagation velocity and assessment of diastolic function during abdominal aortic aneurysm repair. J Cardiothorac Vasc Anesth 2007, 21:486-491.

38. Hettwer S, Panzner-Grote B, Witthaut R, Werdan K: Isolated diastolic dysfunction--diagnostic value of tissue Doppler imaging, colour Mmode and N-terminal pro B-type natriuretic peptide. Clin Res Cardiol 2007, 96:874-882.

39. Matyal R, Hess PE, Subramaniam B, Mitchell J, Panzica PJ, Pomposelli F, Mahmood F: Perioperative diastolic dysfunction during vascular surgery and its association with postoperative outcome. J Vasc Surg 2009, 50:70-76.

40. Duncan Al, Lowe BS, Garcia MJ, Xu M, Gillinov AM, Mihaljevic T, Koch CG: Influence of concentric left ventricular remodeling on early mortality after aortic valve replacement. Ann Thorac Surg 2008, 85:2030-2039.

41. Orsinelli DA, Aurigemma GP, Battista S, Krendel S, Gaasch WH: Left ventricular hypertrophy and mortality after aortic valve replacement for aortic stenosis. A high risk subgroup identified by preoperative relative wall thickness. J Am Coll Cardiol 1993, 22:1679-1683.

42. Pedrazzini GB, Masson S, Latini R, Klersy C, Rossi MG, Pasotti E, Faletra FF, Siclari F, Minervini F, Moccetti T, Auricchio A: Comparison of brain natriuretic peptide plasma levels versus logistic EuroSCORE in predicting in-hospital and late postoperative mortality in patients undergoing aortic valve replacement for symptomatic aortic stenosis. Am J Cardiol 2008, 102:749-754.

doi: $10.1186 /$ cc9040

Cite this article as: Licker et al., Preoperative diastolic function predicts the onset of left ventricular dysfunction following aortic valve replacement in high-risk patients with aortic stenosis Critical Care 2010, 14:R101

\section{Submit your next manuscript to BioMed Central and take full advantage of:}

- Convenient online submission

- Thorough peer review

- No space constraints or color figure charges

- Immediate publication on acceptance

- Inclusion in PubMed, CAS, Scopus and Google Scholar

- Research which is freely available for redistribution 